\title{
Mitochondrial Mechanisms in Cerebral Vascular Control: Shared Signaling Pathways with Preconditioning
}

\author{
David W. Busija Prasad V. Katakam \\ Department of Pharmacology, Tulane University School of Medicine, New Orleans, La., USA
}

\begin{abstract}
Key Words
Anoxia - Adenosine triphosphate-sensitive potassium channels - Calcium sparks - Cerebral arteries .

Endothelium · Ischemia - Neurons · Nitric oxide synthase .

Postconditioning $\cdot$ Vascular smooth muscle
\end{abstract}

\begin{abstract}
Mitochondrial-initiated events protect the neurovascular unit against lethal stress via a process called preconditioning, which independently promotes changes in cerebrovascular tone through shared signaling pathways. Activation of adenosine triphosphate (ATP)-dependent potassium channels on the inner mitochondrial membrane (mitoK ATP $_{\text {chan- }}$ nels) is a specific and dependable way to induce protection of neurons, astroglia, and cerebral vascular endothelium. Through the opening of mitoK $\mathrm{K}_{\text {ATP }}$ channels, mitochondrial depolarization leads to activation of protein kinases and transient increases in cytosolic calcium $\left(\mathrm{Ca}^{2+}\right)$ levels that activate terminal mechanisms that protect the neurovascular unit against lethal stress. The release of reactive oxygen species from mitochondria has similar protective effects. Signaling elements of the preconditioning pathways also are involved in the regulation of vascular tone. Activation of mitoK $_{\text {ATP }}$ channels in cerebral arteries causes vasodilation, with cell-specific contributions from the endothelium, vascular smooth muscles, and nerves. Preexisting chronic conditions, such as insulin resistance and/or diabetes, prevent
\end{abstract}

preconditioning and impair relaxation to mitochondrialcentered responses in cerebral arteries. Surprisingly, mitochondrial activation after anoxic or ischemic stress appears to protect cerebral vascular endothelium and promotes the restoration of blood flow; therefore, mitochondria may represent an important, but underutilized target in attenuating vascular dysfunction and brain injury in stroke patients.

(c) 2014 S. Karger AG, Basel

\section{Introduction}

The neurovascular unit is an integrated system of vascular and parenchymal cells and their environment working together to match blood flow to metabolic demand and to maintain brain homeostasis. Mitochondria are double membrane organelles which generate chemical energy in the form of adenosine triphosphate (ATP), which is distributed within cells and promotes the varied activities of the diverse cell types comprising the neurovascular unit [endothelium, vascular smooth muscle (VSM), astroglia, perivascular neurons, parenchymal neurons, pericytes, and microglia]. Although traditionally understood solely as energy producers and relegated to that role, we now appreciate that mitochondria are involved in diverse adaptive activities, such as promotion of basal cellular functions, cellular protection, and regulation of vascular tone. Evidence also shows that mitochon-

\section{KARGER}

E-Mail karger@karger.com

www.karger.com/jvr
(C) 2014 S. Karger AG, Basel

1018-1172/14/0513-0175\$39.50/0
Prof. David W. Busija

Department of Pharmacology, Tulane University School of Medicine 1430 Tulane Avenue, SL 83

New Orleans, LA 70112-2632 (USA)

E-Mail dbusija@tulane.edu 
drial morphology and function show plasticity and adaptability and can be affected by many factors [1-5]; on the other hand, mitochondrial-centered mechanisms can promote apoptotic and necrotic cell death $[6,7]$. The purpose of this review is to critically examine the role of mitochondrial-based mechanisms on the tone of cerebral resistance vessels. Specifically, we will examine how the selective targeting of mitochondria in the several cell types comprising the neurovascular unit leads to changes in cerebral vascular tone. The studies on cerebral vascular control in our laboratory originated from studies of preand postconditioning mechanisms in the neurovascular unit when we realized that identical pathways are involved and effects may be interactive. This discussion is limited to the systemic circulation; mitochondrial mechanisms in the pulmonary circulation are different [8]. We will show that even relatively mild metabolic stress, such as that which occurs with insulin resistance (IR), a prediabetic condition that impairs preconditioning, can dramatically affect mitochondrial-related events in the cerebral vasculature. Ultimately, we will present evidence suggesting that mitochondrial activation may unexpectedly benefit the cerebral vasculature after ischemia/anoxia and thus decrease morbidity and mortality in stroke patients. Several excellent reviews which focus primarily on peripheral endothelium [9-11] or VSM [12] have been published recently and emphasize the importance of this emerging research area. However, this is the first review to show the similarities between the preconditioning and vascular control pathways and to explore the integration of mitochondrial-based signals arising from multiple cell types into the final vascular response in normal and disease states.

\section{Mitochondrial Essentials}

Important structural features of mitochondria are an outer, relatively permeable membrane, a relatively impermeable inner membrane, the intermembrane space, extensions of the inner membrane called cristae, and the intracristae spaces referred to as the matrix $[13,14]$. Each anatomical component has a specific function which, when integrated, is essential for the optimal production and transfer of energy throughout the mitochondria and into the cytosol. The Krebs cycle is located in the matrix and the complexes associated with the electron transport chain are embedded in the inner mitochondrial membrane. The mitochondrial membrane potential $\left(\Delta \psi_{\mathrm{m}}\right)$ across the inner membrane, which is normally main-

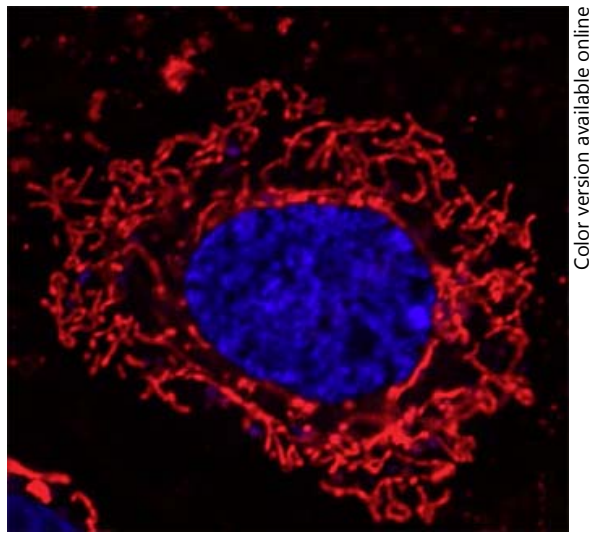

Fig. 1. Mitochondrial morphology within a cerebral vascular endothelial cell. The mitochondria (red) and the nuclei (blue) of live rat brain microvascular endothelial cells were stained using mitochondrial stain $\left(1: 10,000 ; 1_{\mathrm{ex}}: 514 \mathrm{~nm}\right.$ and $\left.\mathrm{l}_{\mathrm{em}}: 538-681 \mathrm{~nm}\right)$ and Hoechst nuclear stain $\left(1: 1,000 ; 1_{\mathrm{ex}}: 405 \mathrm{~nm}\right.$ and $\left.\mathrm{l}_{\mathrm{em}}: 410-585 \mathrm{~nm}\right)$, respectively (Chromeo ${ }^{\mathrm{TM}}$ live cell mitochondrial staining kit; Active Motif, Carlsbad, Calif., USA). Fluorescence images were obtained using LSM 710 AxioObserver (Zeiss, Hamburg, Germany) with a plan-apochromat $\times 63$, numerical aperture 1.4 , oil immersion objective.

tained at approximately $-180 \mathrm{mV}$, provides the proton difference used to drive the synthesis of ATP by the electron transport chain. Several diagnostic and therapeutic approaches take advantage of this negative membrane potential to target positively charged agents specifically to the mitochondria [14-17]. Detailed descriptions of ATP production by non-mitochondrial glycolysis as well as the mitochondrial electron transport chain are widely available $[18,19]$.

Individual mitochondria are not static entities, rather they are dynamic and can move from one location to another within cells, form networks with other mitochondria or cellular structures (fig. 1,2), and undergo replication and fission/fusion in response to physiological and pathological stimuli $[5,15,20-22]$. Because the number and length of cristae are positively related to the ATPgenerating potential, it appears that changes in the location, number, size, and shape of mitochondria under physiological conditions are determined by the energy needs within a cell [23]. Mitochondria in VSM appear to be particularly mobile during cellular migration following vascular damage [24]. In addition to individual mitochondria forming networks within cells (fig. 1,2), the mitochondrial outer membranes are often connected or closely juxtaposed with the membranes of the endoplas$\mathrm{mic} /$ sarcoplasmic reticulum (SR; fig. 2), i.e. cellular structures which are involved in calcium storage and release 
Fig. 2. Lower (a) and higher magnifications (b) of VSM cells from cerebral arteries from normal rats showing clustering of mitochondria $(\mathrm{m})$ and SR in distinct locations as well as isolated mitochondria. Arteries were fixed in $2.5 \%$ glutaraldehyde and postfixed in $1 \%$ osmium tetroxide and embedded in Epon 812. Ultrathin sections (80-90 nm) were mounted on Formvarcoated nickel (200-mesh) grids, air dried, and stained with $4.7 \%$ uranyl acetate and lead citrate (10 and $2 \mathrm{~min}$, respectively). The sections were put on grids and viewed using an FEI Tecnai BioTwin $120 \mathrm{keV}$ transmission electron microscope with a digital imaging setup (Wake Forest University Health Sciences, Winston-Salem, N.C., USA).
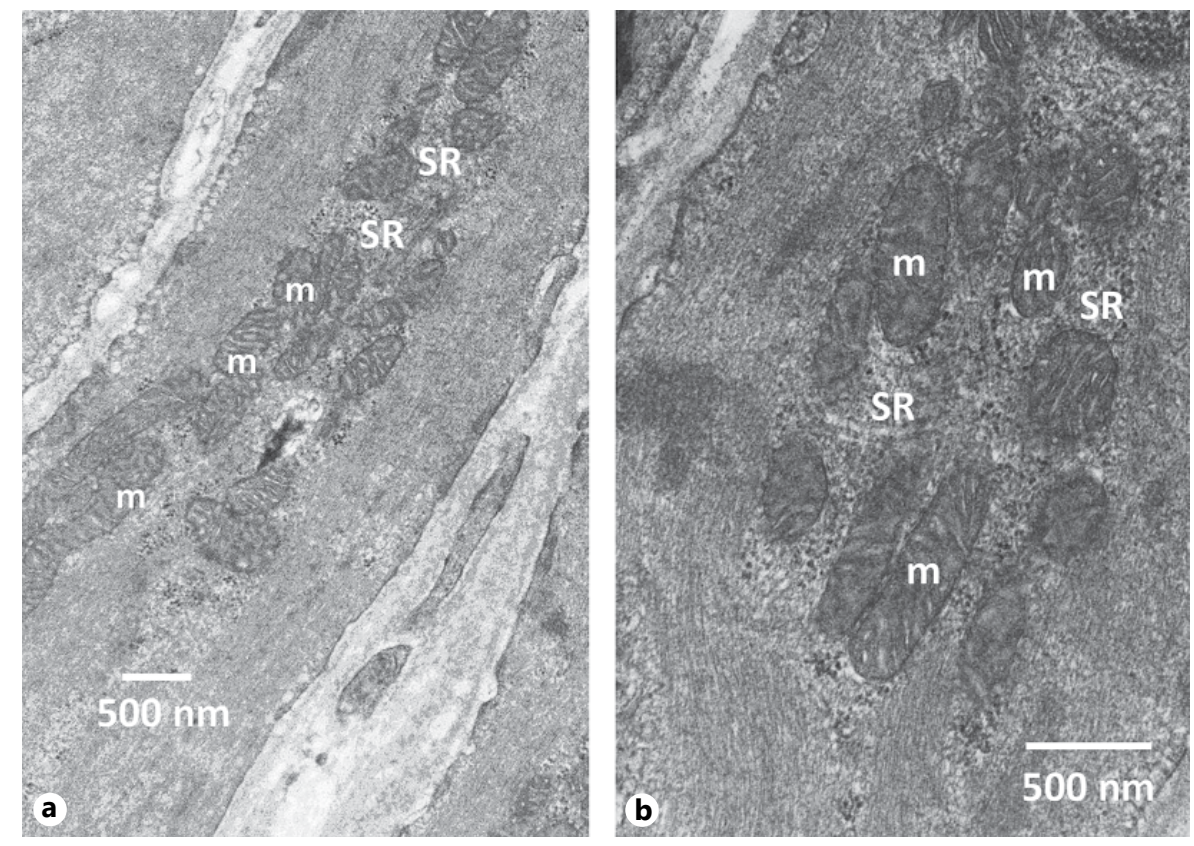

[20]. The complex interplay among mitochondrial, endoplasmic reticulum/SR, and cytosolic calcium has been described in several recent reviews [25-27]. In VSM, some populations of mitochondria and SR appear to be 'bundled' together and this structural feature may restrict movement of certain populations of mitochondria under normal conditions in this vascular cell type (fig. 2) as well as promote the tight functional interactions between mitochondria and SR. However, we are unaware of any systematic studies comparing the mitochondrial morphology and function in the various cell types within the neurovascular unit.

Mitochondria have their own DNA, which is distinct from nuclear DNA, and also possess a protein-synthesizing machinery which produces approximately one half of their proteins while the other half are encoded by nuclear DNA and imported into mitochondria via several different transport mechanisms. The cytochrome $c$ oxidase complex (complex IV), which is the last major component of the electron transport chain and is localized to the inner membrane, is a good example of the dual origins of the proteins present in mitochondria since ten subunits are nuclear in origin and three are synthesized within the mitochondria [28, 29].

Although it has been suggested that mitochondria contain a variant of nitric oxide synthase (NOS), and thus could produce $\mathrm{NO}$ via this enzymatic pathway, there is significant evidence against this view [30-32]. Nonetheless, diffusible NO from non-mitochondrial sources in endothelial cells and neurons [32,33], or NO arising from mitochondria via non-NOS pathways [34], could affect the functioning of the electron transport chain as well as other mitochondrial functions and could combine with superoxide anion to form peroxynitrite $[11,35]$. On the other hand, we have shown that NO production from cytosolic NOS occurs due to endothelial NOS phosphorylation and increased cytosolic calcium following activation of mitochondria with diazoxide or BMS-191095 [32].

\section{Production and Release of Reactive Oxygen Species by Mitochondria}

Mitochondria are constant producers of reactive oxygen species (ROS) which have access to locations throughout the cell as well as to adjacent cells. Although generally thought to be an efficient system, a substantial amount of superoxide anion is continuously 'lost' or released by the electron transport chain at different sites under normal conditions [11, 18]. For example, there is continuous release of superoxide anion in quiescent neurons, astroglia, VSM, and cerebral vascular endothelium [3, 36-38]. Mitochondrial ROS can promote preconditioning as well as directly or indirectly affect cerebral vascular tone, as well as influence other cellular functions.

Superoxide anion from mitochondrial and other cellular locations appears to be an important, if not essen- 
tial, signaling agent involved in the maintenance of basal cell functions such that prolonged suppression of ROS availability is detrimental to cell viability [39]. Superoxide anion acting at sites within the mitochondria or following transport across the inner mitochondrial membrane can influence events throughout the cell. It has been suggested that superoxide anion can leave the mitochondria via voltage-dependent anion channels [40, 41]. However, these channels are located in the outer, more porous mitochondrial membrane and it is not clear how superoxide anion would transverse the inner mitochondrial membrane. Alternatively, superoxide anion formed at complex III may be released into either the matrix or the intermembrane space during certain conditions and then may be transported across the outer mitochondrial membrane by voltage-dependent anion channels [27, 42]. Superoxide anion can also leave the matrix [43] following enzymatic conversion to hydrogen peroxide through aquaporin-like channels in the inner mitochondrial membrane [44-46]. Hydrogen peroxide is considered to be less reactive and has a longer half-life than superoxide anion [47] and can be produced directly by mitochondria under certain conditions $[47,48]$. A number of factors, such as substrate availability, status of the electron transport chain complexes, and the composition of the local environment, are able to affect mitochondrial production of ROS [47]. In addition, physical distortion of the relationship between the two mitochondrial membranes caused by increased shear stress in the endothelium leads to enhanced ROS release by mitochondria [11]. It has generally been accepted that mitochondrial depolarization is always accompanied by enhanced ROS release. However, as described in detail below, mitochondrial depolarization and enhanced ROS production are not necessarily linked and can occur separately under a variety of conditions.

The primary sites of superoxide anion production and release are complex I (NADH-ubiquinone oxidoreductase), complex II (succinate dehydrogenase, SDH), and complex III (ubiquinol-cyctochrome c oxidoreductase). Complexes I and II accept electrons from $\mathrm{NADH}+\mathrm{H}^{+}$ and $\mathrm{FADH}_{2}$, respectively, which are transferred to complex III and finally to complex IV (cytochrome c oxidase), where the final electron acceptor is oxygen and the final product is water $[48,49]$. Superoxide anion from these three complexes is released into the matrix. A number of metabolic poisons are available, which inhibit one or more of the respiratory chain complexes: rotenone: complex I; 3-nitropropionic acid (3-NPA): complex II; antimycin A: complex III; cyanide: complex IV; and oligomy- cin: complex V. The result of inhibition, especially of complexes I-III, is enhanced ROS release.

Although 'normal' continuous release of ROS from mitochondria appears to play a positive role in the maintenance of basal cellular function, transiently elevated ROS levels can promote selective protein synthesis, preconditioning, and changes in vascular tone. However, chronically but modestly elevated ROS production by mitochondria can lead to cellular dysfunction. For example, we have shown that a mutation in the inner mitochondrial membrane peptidase 2-like (Immp2l) gene leads to chronically enhanced ROS release by mitochondria and subsequently causes reduced vascular dilation to carbachol in mesenteric arteries [50]. Similarly, chronically elevated mitochondrial ROS production due to the metabolic syndrome impairs cerebral vascular function through multiple mechanisms $[51,52]$. It also has been reported that a genetic deficiency in MnSOD in mice increases basal superoxide levels in cerebral arteries and aorta [53]. Additionally, chronic inhibition of complex I by rotenone blocks ischemia-induced collateral artery growth in the coronary circulation via activation of adenosine monophosphate (AMP)-activated kinase and the subsequent inhibition of mTOR and p70 ribosomal S6 kinase [54]. Higher levels of cellular ROS, which occur during injury, can lead to cell death via both mitochondrial and non-mitochondrial pathways, especially in metabolically compromised conditions [7, 55].

Production of ROS by mitochondria appears to be an organelle-independent process under most basal conditions, but recent reports indicate that ROS production by mitochondria can either promote ROS production by the extramitochondrial NADPH oxidase system or, vice ver$s a$, via a positive feedback system $[27,56,57]$. Thus, the interaction between the mitochondria and the cytosolic NADPH oxidase axis leads to cellular damage due to excessive production of ROS. The best example of this interaction occurs with the exposure of vascular and nonvascular cells to angiotensin II $[56,58]$. Deficiency in MnSOD leads to cerebral vascular endothelial dysfunction, especially in aged mice, to angiotensin II $[59,60]$.

\section{Mitochondrial Depolarization and Related Events}

The most reproducible and robust approach to depolarizing mitochondria experimentally can be achieved by targeting the mitochondrial ATP-sensitive potassium $\left(\right.$ mitoK $\left._{\mathrm{ATP}}\right)$ channel on the inner mitochondrial mem- 
brane with drugs such as BMS-191095 or diazoxide. The physical structure of mitoK $\mathrm{K}_{\mathrm{ATP}}$ channels is not yet known with certainty but appears to differ substantially from the previously described plasmalemmal $\mathrm{K}_{\mathrm{ATP}}$ channels [6165]. Nonetheless, the pharmacological identification and selectivity to agonists of the mitoK $\mathrm{ATP}_{\mathrm{AT}}$ channels are convincing to the majority of investigators. Recent evidence indicates that the renal outer medullary potassium channel (ROMK) is a component of the $\mathrm{K}^{+}$channel of the cardiac mitoK $_{\text {ATP }}$ [62]. The same researchers also showed that overexpression and suppression of ROMK promoted or reduced preconditioning, respectively. SDH might also be involved in either the assembly or function of the mitoK $_{\text {ATP }}$ channel $[66,67]$. Nonetheless, additional studies are needed to define completely the structure of the mito $_{\mathrm{ATP}}$ channels.

Isolated mitochondria and mitochondria in situ in cultured cells, tissue slices, and in isolated pressurized cerebral arteries depolarize in a dose-dependent manner to selective mitoK $_{\text {ATP }}$ channel openers such as diazoxide and BMS-191095 [36, 38], and mitoK $\mathrm{ATP}_{\mathrm{AT}}$ channel activity is affected by endogenous factors such as the adenosine diphosphate (ADP)/ATP ratio [61], peroxynitrite [64, $65]$, superoxide anion $[7,65]$, and cytosolic protein kinase $\mathrm{C}(\mathrm{PKC}) \varepsilon[68,69]$. Nonetheless, we expect that other, yet unidentified, physiological and pathological factors will be able to directly or indirectly activate mitochondria, including the mitoK $\mathrm{K}_{\mathrm{ATP}}$ channel. The classical $\mathrm{K}_{\mathrm{ATP}}$ channel antagonists glibenclamide and 5-hydroxydecanoic acid, which needs to be metabolized before becoming active [70], block the actions of diazoxide, BMS-191095, and/or PKCe $[36,68,71]$. Diazoxide, a drug previously used against acute hypertension or hypoglycemia, is the most commonly used mitoK $\mathrm{K}_{\mathrm{ATP}}$ channel opener [72], but it has the additional effect of inhibiting SDH (complex II), especially at high doses $[73,74]$. Diazoxide also readily crosses the blood-brain barrier (BBB) and thus is effective in the brain when given intravenously [75]. Although applications of diazoxide or BMS-191095 depolarize mitochondria, diazoxide, but not BMS-191095, also causes the liberation of ROS [76], an event secondary to SDH inhibition according to our findings. This view is supported by examination of the effects of the specific inhibitor of $\mathrm{SDH}, 3-\mathrm{NPA}$, which increases ROS production by mitochondria [71] and also induces preconditioning [77] and changes in vascular tone [52]. Nonetheless, the primary actions of diazoxide on the cells of the neurovascular unit are still specific to mitochondria $[74,76]$, and the associated ROS increase appears to enhance the degree of depolarization $[64,65]$. In contrast, BMS-191095 is very se- lective for mitoK $\mathrm{K}_{\mathrm{ATP}}$ channels and has no known nonspecific effects to complicate the interpretation of the results $[76,78,79]$.

A potential role for mitochondrial calcium-activated potassium $\left(\right.$ mito $_{\mathrm{Ca}}$ ) channels in depolarizing mitochondria has been suggested based primarily on the use of the multiple target drug NS1619 [80]. Although NS1619 results in mitochondrial depolarization, it seems likely that, at least in neurons, effects are due to other factors, such as inhibition of complex I and subsequent increased release of ROS [81, 82]. Given the multiple potential sites of action of NS1619 within various cell types, it is also possible that mitochondrial effects of this drug are secondary to non-mitochondrial events. Nonetheless, more research in this area is warranted and the development of more specific agonists would aid these efforts.

\section{Mitochondrial Membrane Potential and ROS Production Independence}

The use of BMS-191095 has led to findings which challenge accepted views concerning the linkage between mitochondrial depolarization and enhanced mitochondrial ROS release. The selectivity of BMS- 191095 for mitoK $\mathrm{ATP}_{\mathrm{AT}}$ channels and the failure to detect nonspecific effects [76, $78,79]$, which complicate the interpretation of results, have shown that it is possible to depolarize mitochondria without eliciting the enhanced release of ROS in a variety of cells, including neurons, cerebral vascular endothelium, and cerebral VSM. The previous concept linking mitochondrial membrane potential and ROS release was developed using inhibitors of the electron transport chain which, in addition to increasing ROS release from complexes I-III, probably depolarized mitochondria via reduced ATP availability necessary for maintaining the negative transmembrane potential. The recent findings with BMS-191095, which allow dissociation between mitochondrial depolarization and mitochondrial ROS production, are supported by other laboratories [40, 83] as well as other experimental approaches in our laboratory [84]. The dissociation between mitochondrial membrane potential and ROS release is not absolute, however, but probably occurs within a limited range of depolarization. The relative independence of the mitochondrial membrane potential from ROS production and release, with the subsequent induction of different signaling pathways, underscores the versatility of mitochondria to initiate appropriate and selective cellular responses to varied stimuli. 


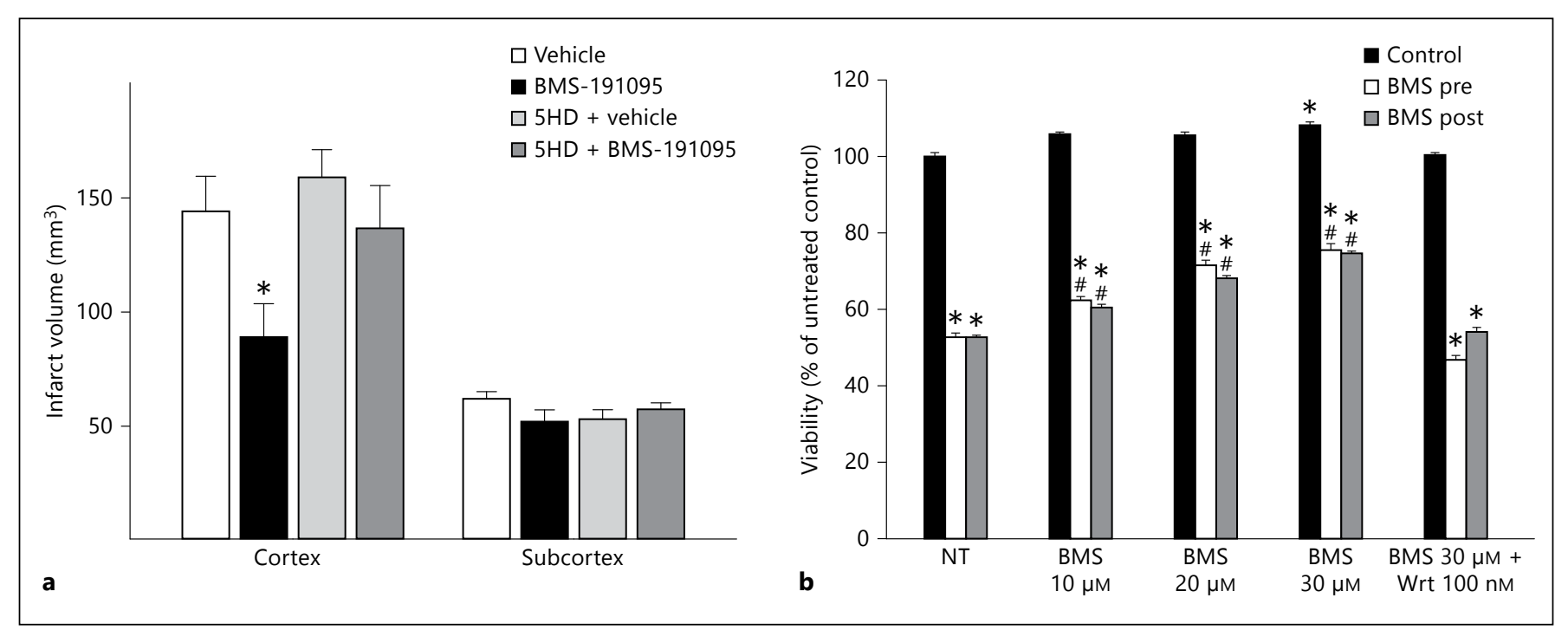

Fig. 3. Examples of preconditioning (pre) and postconditioning (post) with the mitoK ${ }_{\text {ATP }}$ channel opener BMS-191095. a BMS191095 protected the rat brain in vivo against 90 min of middle cerebral artery occlusion when given before ischemia [36]. b Original, unpublished data showing that BMS-191095, when given prior to or following OGD, improved survival of cultured rat cerebral

\section{Role of Mitochondria in Preconditioning}

Preconditioning represents the condition in which transient exposure of cells to an initiating event leads to protection against subsequent, potentially lethal stimuli (fig. 3) by limiting ROS availability, suppressing large increases in cytosolic levels of free calcium, and/or by other mechanisms which promote cell survivability (fig. 4). The acute signaling mechanisms promoting preconditioning also affect cerebral vascular tone (fig. 5), and the chronic changes in vascular cells following preconditioning, involving altered cellular calcium and ROS dynamics, probably affect subsequent cerebral artery responses to changing conditions. However, this possibility has not been tested.

Beginning with our original observation [85], a number of independent studies by other laboratories have established that mitochondrial-centered mechanisms are important initiators of the pre- and postconditioning response in neurons, astroglia, and cerebral endothelial cells [1, 49, 72, 75, 76, 85-94]. Mitochondrialcentered preconditioning also occurs in tissues such as the myocardium [51], skeletal muscle [79], and peripheral endothelium [90, 95]. Important mitochondrialspecific targets for inducing preconditioning by pharmacological approaches include: (1) potassium chan- endothelial cells. Inhibition of PI3K with wortmannin (Wrt) counteracted beneficial effects of BMS-191095 [unpubl. observations]. 5-HD $=5$-Hydroxydecanoic acid. ${ }^{*} \mathrm{p}<0.05$ compared to appropriate control; ${ }^{\#} \mathrm{p}<0.05$, BMS treatment compared to no treatment or Wrt treatment.

nels located on the inner mitochondrial membrane; (2) respiratory chain enzymes, and (3) metabolic substrate restriction.

Although the mitochondrial-initiated mechanisms involved in preconditioning are not fully understood, the activation of protein kinases, transient but modest calcium fluxes, and/or ROS production appear to be essential signaling events leading to preconditioning (fig. 4). There are two general types of preconditioning: immediate and delayed. Immediate preconditioning occurs within minutes of the initiating stimulus and lasts for several hours before disappearing, whereas delayed preconditioning takes several hours to develop and persists for several days $[96,97]$. Given these temporal aspects, it seems probable that immediate preconditioning primarily involves changes in the activity or function of enzymes, second messengers, and ion channels already present, whereas delayed preconditioning is principally due to de novo protein synthesis, such as increased catalase levels [76]. Many subsequent signaling events not only induce preconditioning but also promote changes in vascular tone. Postconditioning, in which the initiating event occurs following the onset of the potentially lethal event $[93,98]$, has also been reported, and its mechanisms, especially those involving mitochondria and the phosphoinositide 3-kinase (PI3K)/protein ki- 


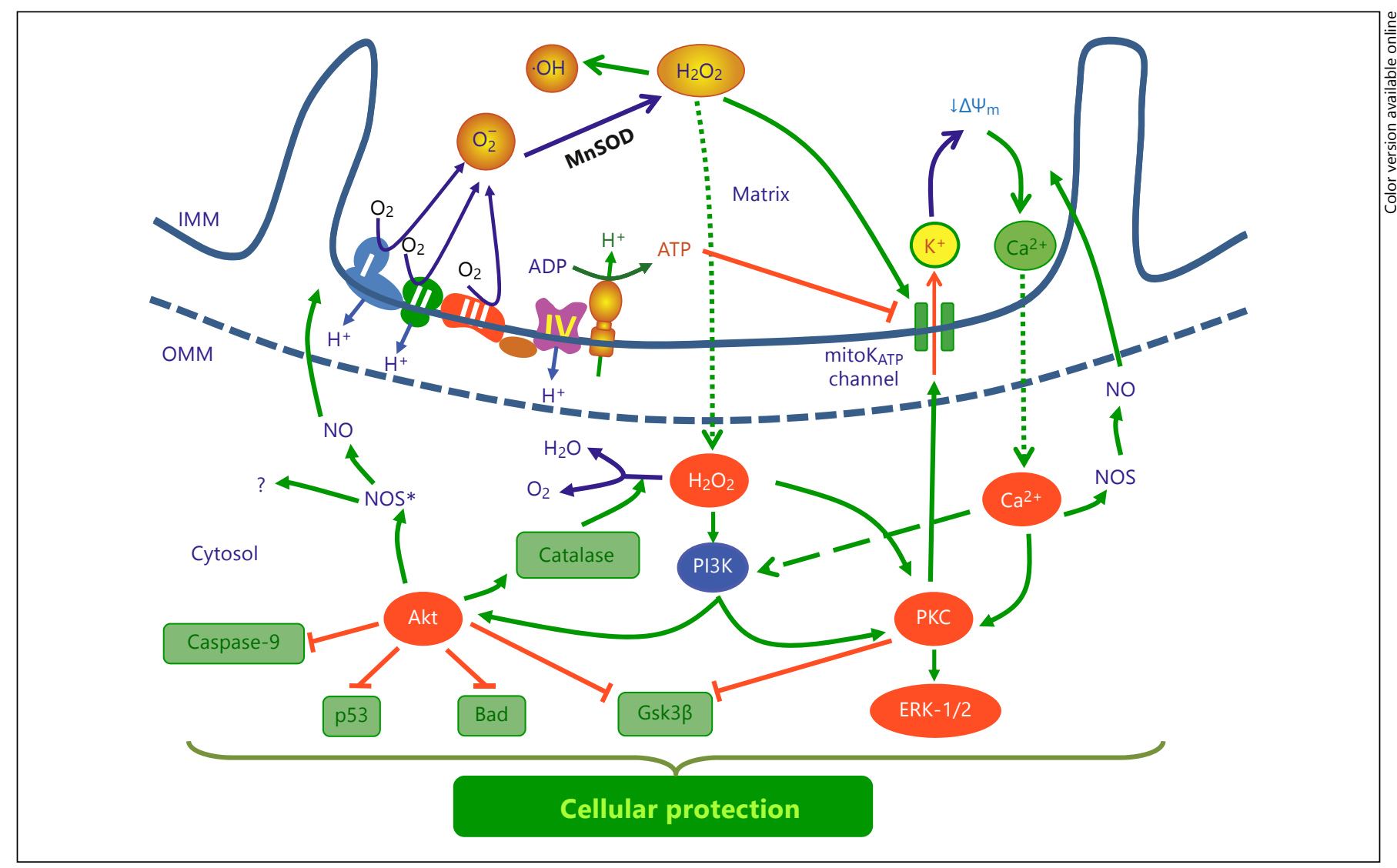

Fig. 4. Schematic illustration showing signaling events (red circles) and ultimate mechanisms (green boxes) resulting in cellular protection following opening of mitoK $\mathrm{K}_{\mathrm{ATP}}$ channels or liberation of ROS from the protein complexes which form the electron trans- port chain. $\mathrm{OMM}=$ Outer mitochondrial membrane; $\mathrm{IMM}=$ inner mitochondrial membrane; $\mathrm{O}_{2}^{-}=$superoxide anion; Gsk3 $\beta=$ phosphoglycogen synthase kinase $3 \beta$; $\mathrm{Bad}=\mathrm{Bcl}-2$ associated death promoter; NOS $^{*}=$ phosphorylated NOS.
Fig. 5. Schematic illustration showing detailed signaling events and ultimate mechanisms from endothelium and VSM resulting in integrated changes in vascular tone following opening of mitoK $\mathrm{K}_{\mathrm{ATP}}$ channels or liberation of ROS from the protein complexes which form the electron transport chain.

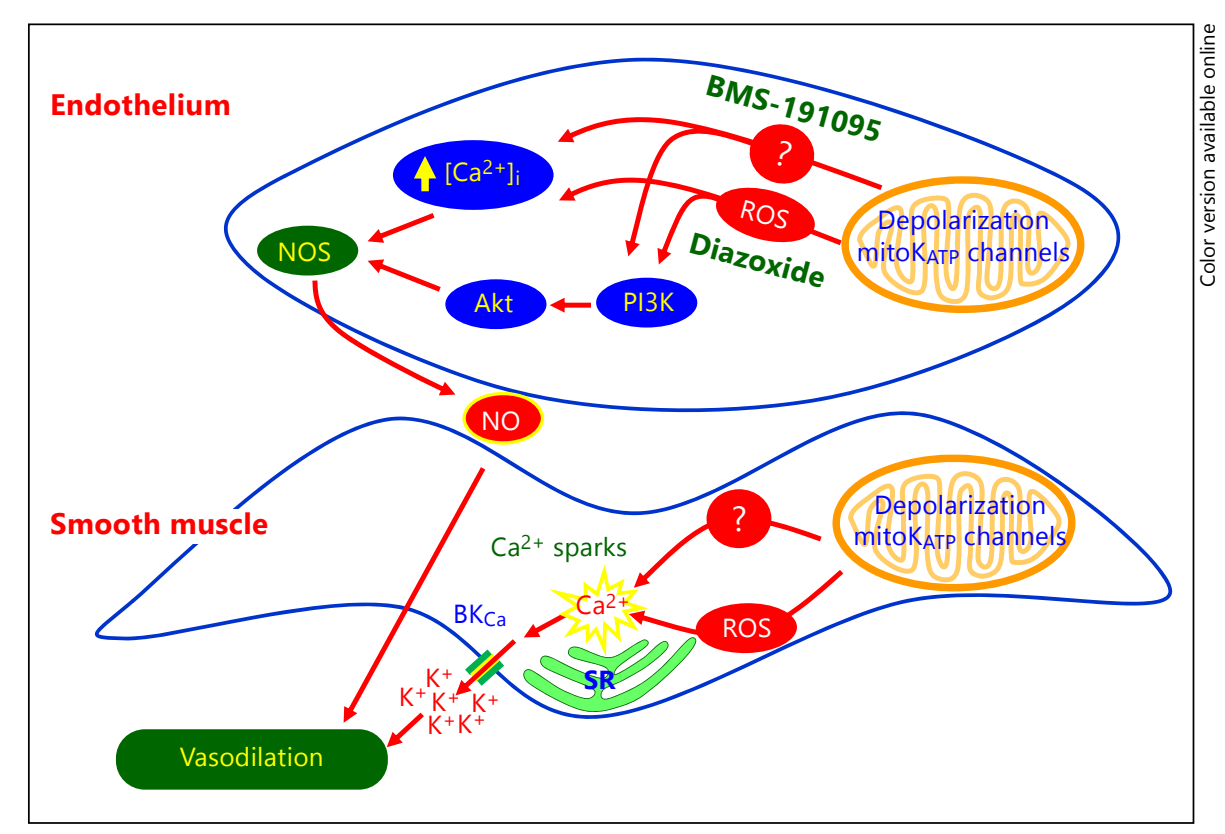


nase B (Akt) signaling pathway, appear to be similar to those that promote preconditioning. In cultures of primary rat brain microvascular endothelium, we found that postconditioning was as effective as preconditioning against oxygen-glucose deprivation (OGD; fig. 3), and that activation of the PI3K/Akt signaling pathway was essential in both types of cellular protection (fig. 3, 4). The ability of mitochondria from cerebral vascular endothelium to function at the end of OGD, where almost $50 \%$ of cells would eventually die without treatment, indicates that mitochondria remain a potentially useful target in stroke patients.

Although some authors have presented a case for a role of mitoK $_{\mathrm{Ca}}$ channels in promoting preconditioning based primarily on the use of NS1619 [99, 100], experimental evidence is not convincing due to the lack of a specific mito $_{\mathrm{Ca}}$ channel opener and the numerous nonspecific effects of NS1619. We were the first to show that NS1619 is both neuroprotective [101] and vasoactive in cerebral arteries [102], and that preconditioning of neurons by this agent was likely due to inhibition of complex I or other mechanisms rather than a mitoK $\mathrm{K}_{\mathrm{Ca}}$ channel-specific effect $[81,82,103,104]$. Administration of NS1619 dilates other peripheral arteries [105].

Removal or reductions in key metabolic substrates, such as glucose and oxygen, can induce preconditioning and changes in cerebral vascular tone. For example, transient withdrawal of glucose, the major energy substrate for neurons, as well as removal of amino acids, results in mitochondrial depolarization and reduced ATP production, and in delayed tolerance against various insults, such as OGD, glutamate excitotoxicity, and exogenous hydrogen peroxide toxicity [106]. Adenosine, AMP, ADP, and ATP are vasoactive stimuli in cerebral arteries $[107,108]$.

\section{Mitochondria and Cerebral Vascular Tone}

Our studies of preconditioning indicated that many of the signaling events associated with the induction of mitochondrial-targeted cellular protection also affect cerebrovascular tone (fig. 4, 5). Although it is known that ATP, from either glycolysis or oxidative phosphorylation, as well as the metabolites adenosine, AMP, and ADP $[92,109]$ can alter cerebrovascular tone via plasmalemmal purinergic receptors [110], only a few studies have examined direct mitochondrial influences on the diameter of cerebral resistance vessels $[2,32,52,111$, $112]$. Thus, the study of mitochondrial effects on the ce- rebral vasculature is a relatively unexplored field. Only a few studies have examined mitochondrial influences on the cerebral vasculature during disease states, but increasing amounts of information are rapidly becoming available in other systemic circulations $[10,11,78]$ and VSM [12]. Although the majority of studies involving mitochondrial influences on the cerebral vasculature have used pharmacological agents, a few studies have used genetically altered mice in which a deficiency in MnSOD has resulted in increased basal levels of superoxide anion and endothelial dysfunction in cerebral arteries, especially with exposure to angiotensin II and aging in male rats [59].

\section{Vascular Smooth Muscle}

Cheranov and Jaggar [113] and Xi et al. [111] were the first to show that activation of mitochondria by diazoxide promoted relaxation of VSM cells in endothelium-denuded cerebral arteries or freshly dissociated VSM via a mechanism primarily involving ROS. Thus, diazoxide application enhanced the generation of ROS from mitochondria, which sequentially caused the activation of ryanodine-sensitive $\mathrm{Ca}^{2+}$ channels on the SR, the generation of $\mathrm{Ca}^{2+}$ transients called ' $\mathrm{Ca}^{2+}$ sparks', and the opening of adjacent large-conductance $\mathrm{Ca}^{2+}$-activated $\mathrm{K}^{+}$ $\left(\mathrm{BK}_{\mathrm{Ca}}\right)$ channels on the plasma membrane. The resulting $\mathrm{K}^{+}$efflux led to VSM hyperpolarization, decreased global intracellular $\mathrm{Ca}^{2+}$, and vasodilation. We have reported similar findings in endothelium-denuded arteries with diazoxide $[3,32,52]$. The role of mitochondrial ROS resulting from inhibition of SDH in promoting VSM relaxation in cerebral arteries is also shown by application of 3-NPA [52]. However, BMS-191095 has a similar effect in VSM without the involvement of ROS [3, 32] (fig. 5). Thus, BMS-191095 does not increase vascular cytosolic or mitochondrial levels of ROS in any of the cell types that we have examined, and dilation to BMS-191095 is not affected by ROS scavengers; nonetheless, calcium spark activity increases with BMS-191095 application. The reasons for these differences in findings are unclear but taken together underscore the importance and robustness of mitochondrial mechanisms in promoting relaxation of VSM. We speculate that there is direct electrophysiological coupling between mitochondria and SR in VSM and/ or that microdomains involving the outer mitochondrial and SR membranes link functional interactions between these two organelles. The close physical association and thus the possibility of direct coupling of mitochondria and SR are clearly seen with electron microscopy in cerebral VSM (fig. 2). 


\section{Endothelium}

Mitochondrial content in the cerebrovascular endothelium is higher than in the endothelium of other peripheral circulations, probably due to the transport requirements of the BBB [114]. We investigated the contribution of mitochondrial factors arising within the endothelium on the integrated response of intact cerebral arteries using several approaches. First, removal of the endothelium altered the vasodilation to diazoxide and BMS-191095, implying that traditional endothelium-derived factors such as $\mathrm{NO}$ and prostaglandins contribute to changes in vascular tone $[32,52]$. However, the endothelial effects are complex. In intact blood vessels, inhibition of NOS with L-NAME administration reduced relaxation to diazoxide indicating a dilator role of NO. In contrast, inhibition of cyclooxygenase with indomethacin enhanced dilation in diazoxide-treated arteries, implying a role for constrictor prostanoids. Indomethacin did not affect vasodilation in endothelium-denuded arteries. Similar results were obtained with BMS-191095 with respect to L-NAME administration [32]. However, unlike diazoxide, indomethacin administration did not enhance dilation to BMS-191095, suggesting that an ROS-mediated mechanism leading to cyclooxygenase activation may account for these differences. Fluorescence and electron spin resonance measurements of $\mathrm{NO}$ in intact arteries or cultured cerebral microvascular endothelial cells confirmed the production of NO in response to diazoxide and BMS-191095. In addition, fluorescence measurements showed that a global increase in free cytosolic calcium rather than calcium sparks was temporally associated with increased NO production. We have demonstrated that NO arises from cytosolic rather than mitochondrial sites during normal conditions [30-32]. Thus, BMS-191095 and diazoxide application led to mitochondrial depolarization, activation of eNOS by calcium- and phosphorylation-specific mechanisms, production of NO, and relaxation of VSM (fig. 5). Zhang and Gutterman [48] showed that a physiological stimulus such as increased shear stress is able to directly activate mitochondria in coronary endothelial cells via filamentous connections and dilate coronary arteries via effects of hydrogen peroxide. Whether this endothelium-specific mechanism operates in response to increases in flow or shear stress in cerebral arteries is unclear, since alternative mechanisms promoting either dilation or constriction in cerebral resistance vessels of different sizes and locations have been proposed by Koller and Toth [115]. Mitochondrial depolarization by the protonophore carbonyl cyanide 4-(trifluoromethoxy)phenylhydrazone in endothelial tubes from mesenteric arteries has also been shown to activate calcium-activated $\mathrm{K}^{+}$channels presumably by elevation of endothelial $\mathrm{Ca}^{2+}[116]$. Even though precise mechanisms may be different in cerebral and coronary arteries, the common feature is that stimulation of mitochondria is able to liberate substances by the endothelium which can affect VSM tone.

Mitochondrial numbers and composition in the cerebral vascular endothelium are affected by factors such as ischemic stress [unpubl. observations] and hormones such as estrogen [112,117]. Administration of $17 \beta$-estradiol profoundly affects mitochondrial function in cerebral blood vessels via estrogen receptor $\alpha$, thereby enhancing efficiency of energy production and suppressing mitochondrial oxidative stress. These results indicate that ovarian hormones normally act through a distinctive regulatory pathway involving peroxisome proliferator-activated receptor $\gamma$ coactivator 1 to support cerebral endothelial mitochondrial content and guide mitochondrial function to favor ATP coupling and ROS protection. An interesting observation is that female mice with MnSOD deficiency are largely protected from cerebrovascular dysfunction compared with male mice [59]. The basis for this gender difference is unclear at this time but may reflect yet unknown compensatory mechanisms in the vascular mitochondria of female mice.

\section{Perivascular and Parenchymal Nerves}

The potential for mitochondrial influences from perivascular nerves or parenchymal neurons on cerebral vascular responses has never been specifically investigated. However, there are a number of factors suggesting an important neuronal contribution from both sources. Mitochondrial density is relatively high in perivascular nerves observed under confocal imaging [unpubl. observations] and as seen in our preconditioning studies, mitochondria in neurons are responsive to both diazoxide and BMS191095 [36]. Cerebral arteries receive innervation from sympathetic, parasympathetic, and nitroxidergic nerves [118-120]. These speculations are supported by our preliminary studies. Specific inhibition of neuronal NOS with 7-nitroindazole in perivascular nerves, or blockade of perivascular nerves with tetrodotoxin, inhibits dilation in both intact and denuded cerebral arteries to BMS191095 [121]. The effects of tetrodotoxin may be due to interactions between different types of perivascular nerves or between astroglia and perivascular nerves. Electrical activation of perivascular nerves, which might mimic superfusion with diazoxide and BMS-191095, elicits dilation of cerebral arteries, which is blocked by tetro- 


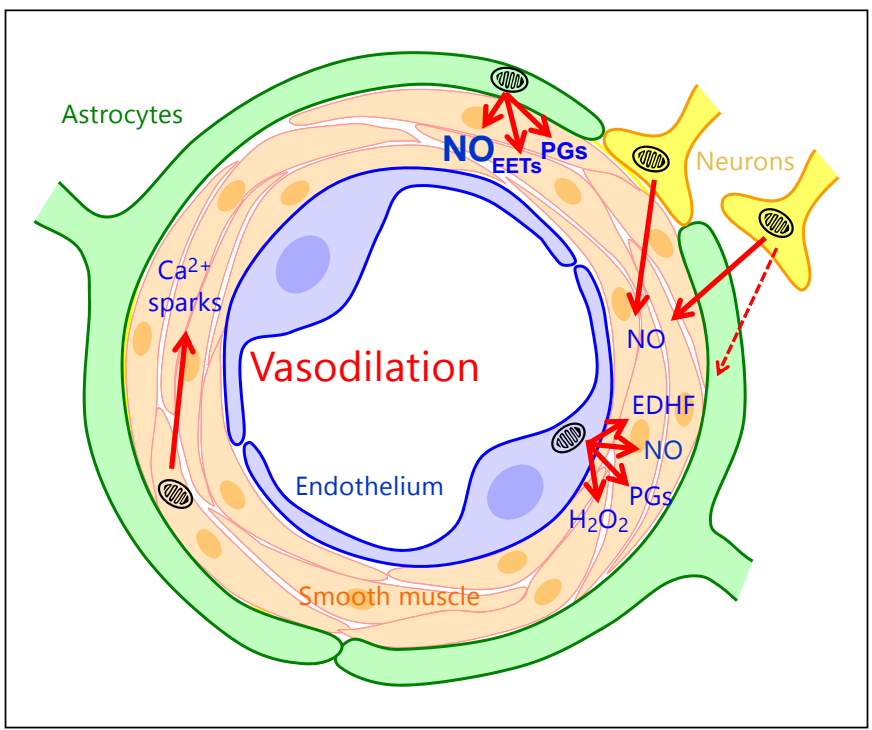

Fig. 6. Schematic illustration showing interaction among mitochondrial influences originating from VSM, endothelium, perivascular nerves, and parenchymal astroglia and neurons. Factors produced following activation of mitochondria by physiological, pharmacological, and pathological stimuli in any of these cell types can affect VSM and the interaction of these factors will determine the final, integrated arterial tone. PGs = Prostaglandins; EDHF = endothelial-derived hyperpolarizing factor; EETs = epoxyeicosatrienoic acids.

dotoxin [122]. Additionally, BMS-191095 depolarizes mitochondria in cultured cortical neurons and enhances NO production by these cells. Thus, in addition to the endothelium, perivascular nerves, parenchymal neurons, and possibly astroglia as well $[37,123]$ can provide mitochondrially initiated vasoactive signals to VSM [74, 124, $125]$ for the final determination of integrated changes in cerebrovascular diameter (fig. 6).

\section{Mitochondria in IR}

IR often precedes the development of type II diabetes by years or decades, and is considered a relatively silent phase of the metabolic syndrome despite developing vascular dysfunction and moderate arterial hypertension. We and others have characterized many of the general cardiovascular and brain effects of this disease $[3,51,52$, 126-128] due to tissue and vascular inflammation and increased basal levels of ROS from both mitochondrial and non-mitochondrial sources $[127,128]$.

We were among the first investigators to demonstrate that several pathological stressors are able to disrupt normal functioning of plasmalemmal $\mathrm{K}_{\mathrm{ATP}}$ channels in cerebral arteries [126-129] and, therefore, it is not surprising that mitoK $_{\mathrm{ATP}}$ channels would be affected in a similar manner. For example, ischemia/reperfusion as well as nutritional and genetic models of IR reduced the function of several types of potassium channels in cerebral VSM, including $\mathrm{K}_{\mathrm{ATP}}$ channels, through mechanisms involving enhanced baseline vascular levels of ROS [126-128]. However, effects of ischemia on $\mathrm{K}_{\mathrm{ATP}}$ channels are transient, so that normal responses return by $4 \mathrm{~h}$ of reperfusion. Thus, ROS scavengers [127], PKC inhibition [126], or anti-inflammation therapies such as statin administration [128] are able to restore normal dilation to potassium channel activators despite continued IR. Even though enhanced ROS from mitochondria is associated with IR, reduced ROS production from $\mathrm{NADPH}$ oxidase results in restored $\mathrm{K}_{\mathrm{ATP}}$ channel function in cerebral arteries. We speculate that ROS-induced ROS production, involving the mitochondrial electron transport chain and NADPH oxidase, might be necessary for the full dysfunction of $\mathrm{K}_{\mathrm{ATP}}$ channels in IR. Similarly, a more severe, acute event, namely ischemia/reperfusion, is able to reduce $\mathrm{K}_{\mathrm{ATP}}$ channel-dependent dilation in cerebral arteries [129]. Additionally, we have shown that immediate preconditioning which is dependent upon activation of mitoK $\mathrm{K}_{\mathrm{ATP}}$ channels is abolished in hearts of IR rats [51]. Thus, ischemic- as well as diazoxide-induced preconditioning fails to protect hearts from ischemia/reperfusion in IR rats whereas both of these approaches limited infarct size in hearts from nonIR rats. In these IR animals, prior to ischemia/reperfusion, a substantial number of the mitochondria in the heart were swollen or showed disruption of the normal pattern for cristae. Moreover, the isolated mitochondria from the hearts of IR animals had reduced responses to diazoxide. An additional finding from this study was that infarct size was enhanced in the hearts from Zucker obese compared with lean rats, which is similar to that which we [130] and others [53] have found in brains of IR, obese mice following middle cerebral artery occlusion. These results may indicate that normal protective mechanisms initiated at the level of the mitochondria are impaired in many common disease states, and thus the brain and other organs are more at risk during ischemic episodes.

Similar to preconditioning, mitochondrial-dependent responses in cerebral arteries are impaired in IR rats [52]. This attenuation of dilation appears to be due to reduced mitochondrial depolarization of VSM as well as reduced ROS generation in response to diazoxide. In 

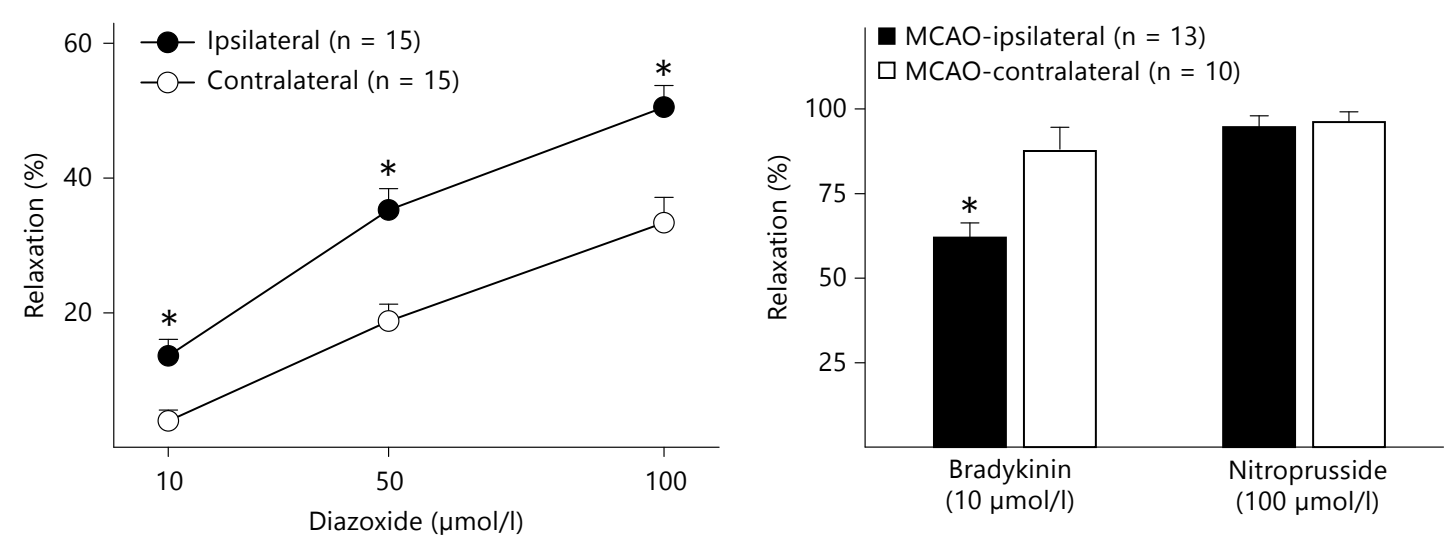

Fig. 7. Original, unpublished data from Wistar rats showing that dilator responses of isolated, pressurized middle cerebral arteries to diazoxide are substantially enhanced compared to the nonischemic, contralateral artery 2 days following 90 min of middle cere-

bral artery occlusion via the filament method [unpubl. observations]. At the same time, dilator responses to other endothelialdependent responses, such as bradykinin, were reduced. ${ }^{*} \mathrm{p}<0.05$. Similar results were found in Sprague-Dawley rats [133].

addition, decreased NO production/bioavailability, despite increased endothelial NOS expression in IR arteries, appears to contribute to diminished relaxation of VSM. We have found similar impairment in cerebrovascular dilation to BMS-191095 in IR animals [32]. An unexpected result was that, in contrast to mitochondrial activation with diazoxide or BMS-191095, dilator responses to 3-NPA were modestly enhanced in arteries from IR rats [52]. Additionally, co-application of 3-NPA with diazoxide led to more than just an additive dilator effect, which was not attenuated in arteries from IR animals. The reason for this effect is unclear, but it seems to indicate that IR interferes with some, but not all vasoactive influences from mitochondria. The potential for the uncoupling of the tight relationship between metabolic need and blood flow in the brain due to cerebrovascular dysfunction associated with IR, as well as the elimination of normal, protective mechanisms involving mitochondria, such as preconditioning, may account for the increased risk and severity of neurological diseases and strokes in patients suffering from the metabolic syndrome. Similar to our findings with IR, anti-ROS treatment restores morphological structure in coronary endothelial cells in a mouse model of type 1 diabetes [131]. In addition, Kizhakekuttu et al. [125] provided evidence that mitochondrial derangements lead to reduced endothelium-induced dilation in human arteries. A possible therapeutic approach might involve the early detection and treatment of IR individuals with the aim toward reducing vascular inflammation and mitochondrial dys-

function prior to the further progression of this chronic disease. We have shown that even very short-term treatment with a statin, which reduced vascular ROS levels and restored normal $\mathrm{K}_{\mathrm{ATP}}$ channel function without lowering blood cholesterol levels, was effective in IR rats [128].

\section{Mitochondria and Cerebral Ischemia}

Although mitochondrial failure is a major cause of cell death due to ischemia, our recent findings indicate that mitochondria in the endothelium may represent a useful target to prevent cell death and restore cerebral blood flow after stroke. Preconditioning before ischemia preserves endothelium-dependent dilation [132] and reduces permeability of the BBB in vivo [75], and postconditioning protects the endothelium in vitro against prior OGD (fig. 3). In recent preliminary studies, we examined the effects of experimental stroke on middle cerebral artery responses 2 days following reperfusion, and found that dilation was greater on the side ipsilateral to the middle cerebral artery occlusion compared with the contralateral, non-stroke side in both Wistar (fig. 7) and Sprague-Dawley rats [133]. At this time, dilator and constrictor responses to other, non-mitochondrial stimuli were reduced in middle cerebral arteries on the stroke side. Thus, not only are endothelial cells responsive to mitochondrial-induced postconditioning after anoxic stress, but vascular responsiveness to mito- 
chondrial activators is also enhanced [133]. Therefore, because strokes occur unpredictably, therapeutic targeting of mitochondria after the onset of ischemic stroke may be a clinically useful approach. Cerebral ischemia, resultant cerebrovascular dysfunction, and parenchymal damage occur unexpectedly following occlusive and hemorrhagic strokes as well as from severe hypotension due to heart attacks and trauma. The only proven therapeutic approach for occlusive strokes is surgical or enzymatic removal of the clot from a cerebral artery, but even after clot removal, patients especially beyond the 3-hour 'window' often suffer from cerebral hypoperfusion, damage to the $\mathrm{BBB}$, and continued parenchymal damage. We believe that activation of mitochondrial mechanisms after the insult may benefit the brain by protecting cerebrovascular cells by preventing further injury to the endothelium and VSM, correcting cerebral hypoperfusion, restoring normal cerebrovascular responsiveness and the $\mathrm{BBB}$, and restricting further neuronal and glial cell death.

\section{Conclusions, Significance, and Perspectives}

We can draw four major conclusions. First, mitochondrial influences are important initiators of pre- and postconditioning in the most vulnerable cell types within the neurovascular unit. Thus, targeting mitochondria may be a useful therapeutic approach to protect the cerebrovasculature and brain of patients prior to elective surgeries and also following the onset of strokes. Second, individual mitochondrial influences from the endothelium, perivascular nerves, and perhaps parenchymal neurons and astroglia are able to contribute to the direct mitochondrial-initiated dilator effects of VSM into a final, integrated change in cerebrovascular tone. Thus, production of vasoactive factors following activation of mitochondria in response to physiological stim- uli in one or several of the cells comprising the neurovascular unit may represent the elusive signaling link between metabolic rate and blood flow. Third, important mitochondrial-derived mechanisms, such as those that induce preconditioning or cause changes in cerebrovascular tone, are disrupted by chronic disease processes such as IR and diabetes, even when signs and symptoms are relatively mild. Thus, direct or indirect targeting of mitochondria in the early stages of the metabolic syndrome might prove to be an effective treatment to reduce morbidity and mortality in these patients related to the increased risk of cardiovascular disease, stroke, and dementia, such as Alzheimer's disease. Fourth, preliminary evidence indicates that mitochondrial mechanisms promoting vasodilation are usually present to some extent following experimental strokes. Thus, targeting mitochondria following a patient's ischemic injury may help correct cerebral hypoperfusion and restore the $\mathrm{BBB}$, and thereby restrict further neuronal and glia cell death.

The study of mitochondrial influences on the vasculature is a rapidly evolving field of investigation; however, there is much research to do in order to understand the intricacies of mitochondrial biology and the mitochondrial mechanisms involved in cerebral vascular control during health and disease. Nonetheless, it seems likely that the manipulation of mitochondrial numbers or function will represent an important therapeutic approach for the future treatment of many chronic and acute disease states.

\section{Acknowledgments}

The study was supported by NIH grants HL-077731, HL030260, HL-065380, and HL-093554. We thank Nancy Busija, MA, CCC-SLP, for editorial assistance. We thank Ken Grant of the Cellular Imaging Shared Resource at Wake Forest University Health Sciences for assistance with electron microscopy.

\section{References}

1 Busija DW, Lacza Z, Rajapakse N, Shimizu K, Kis B, Bari F, Domoki F, Horiguchi T: Targeting mitochondrial ATP-sensitive potassium channels - a novel approach to neuroprotection. Brain Res Rev 2004;46:282-294.

-2 Duckles SP, Krause DN: Cerebrovascular effects of oestrogen: multiplicity of action. Clin Exp Pharmacol Physiol 2007;34:801-808.

3 Katakam PVG, Gordon A, Venkata NLRS, Rutkai I, Busija DW: Diversity of mitochondrial-dependent dilator mechanisms in vas- cular smooth muscle of cerebral arteries from normal and insulin resistant rats. Am J Physi$\mathrm{ol}$, in press.

4 McBride HM, Neuspiel M, Wasiak S: Mitochondria: more than just a powerhouse. Curr Biol 2006;16:R551-R560.

5 Wappler EA, Institoris A, Dutta S, Katakam PV, Busija DW: Mitochondrial dynamics associated with oxygen-glucose deprivation in rat primary neuronal cultures. PLoS One 2013;8:e63206.
6 Halestrap AP: The mitochondrial permeability transition: its molecular mechanism and role in reperfusion injury. Biochem Soc Symp 1999;66:181-203.

-7 Kubli DA, Gustafsson ÅB: Mitochondria and mitophagy: the yin and yang of cell death control. Circ Res 2012;111:1208-1221.

8 Dromparis P, Sutendra G, Michelakis ED: The role of mitochondria in pulmonary vascular remodeling. J Mol Med (Berl) 2010;88: 1003-1010. 
9 Groschner LN, Waldeck-Weiermair M, Malli 25 Chalmers S, Olson ML, MacMillan D, RainR, Graier WF: Endothelial mitochondria less respiration, more integration. Pflugers Arch 2012;464:63-76.

10 Kluge MA, Fetterman JL, Vita JA: Mitochondria and endothelial function. Circ Res 2013; 12:1171-1188.

-11 Widlansky ME, Gutterman DD: Regulation of endothelial function by mitochondrial reactive species. Antioxid Redox Signal 2011;15: 1517-1530.

-12 McCarron JG, Wilson C, Sandison ME, Olson ML, Girkin JM, Saunter C, Chalmers S: From structure to function: mitochondrial morphology, motion and shaping in vascular smooth muscle. J Vasc Res 2013;50:357-371.

13 Jonckheere AI, Smeitink JA, Rodenburg RJ: Mitochondrial ATP synthase: architecture, function and pathology. J Inherit Metab Dis 2012;35:211-225.

14 Davidson SM: Endothelial mitochondria and heart disease. Cardiovasc Res 2010;88:58-66.

-15 Graham D, Huynh NN, Hamilton CA, Beattie E, Smith RA, Cochemé HM, Murphy MP, Dominiczak AF: Mitochondria-targeted antioxidant MitoQ10 improves endothelial function and attenuates cardiac hypertrophy. Hypertension 2009;54:322-328.

16 Kalyanaraman B: Oxidative chemistry of fluorescent dyes: implications in the detection of reactive oxygen and nitrogen species. Biochem Soc Trans 2011;39:1221-1225.

17 Nishikawa T, Edelstein D, Du XL, Yamagishi S, Matsumura T, Kaneda Y, Yorek MA, Beebe D, Oates PJ, Hammes HP, Giardino I, Brownlee M: Normalizing mitochondrial superoxide production blocks three pathways of hyperglycaemic damage. Nature 2000;404:787-790.

18 Dröse S, Brandt U: Molecular mechanisms of superoxide production by the mitochondrial respiratory chain. Adv Exp Med Biol 2012; 748:145-169.

19 Walker JE: The ATP synthase: the understood, the uncertain and the unknown. Biochem Soc Trans 2013;41:1-16.

-20 Dorn GW, Scorrano L: Two close, too close: sarcoplasmic reticulum-mitochondrial crosstalk and cardiomyocyte fate. Circ Res 2010 107:689-699.

-21 Duckles SP, Krause DN: Mechanisms of cerebrovascular protection: oestrogen, inflammation and mitochondria. Acta Physiol 2011; 203:149-154.

22 Zick M, Rabl R, Reichert AS: Cristae formation-linking ultrastructure and function of mitochondria. Biochim Biophys Acta 2008, 1793:5-19.

-23 Hill BG, Benavides GA, Lancaster JR Jr, Ballinger S, Dell'Italia L, Jianhua Z, Darley-Usmar VM: Integration of cellular bioenergetics with mitochondrial quality control and autophagy. Biol Chem 2012;93:1485-1512.

-24 Chalmers S, Saunter C, Wilson C, Coats P, Girkin JM, McCarron JG: Mitochondrial motility and vascular smooth muscle proliferation. Arterioscler Thromb Vasc Biol 2012;32: 3000-3011. bow RD, McCarron JG: Ion channels in smooth muscle: regulation by the sarcoplasmic reticulum and mitochondria. Cell Calci-

26 Dai J, Kuo KH, Leo JM, van Breemen C, Lee $\mathrm{CH}$ : Rearrangement of the close contact between the mitochondria and the sarcoplasmic reticulum in airway smooth muscle. Cell Calcium 2005;37:333-340.

27 Daiber A: Redox signaling (cross-talk) from and to mitochondria involves mitochondrial pores and reactive oxygen species. Biochim Biophys Acta 2010;1797:897-906.

28 Ghezzi D, Zeviani M: Assembly factors of human mitochondrial respiratory chain complexes: physiology and pathophysiology. Adv Exp Med Biol 2012;748:65-106.

29 Lenaz G, Genova ML: Structure and organization of mitochondrial respiratory complexes: a new understanding of an old subject. Antioxid Redox Signal 2010;12:961-1008.

30 Lacza Z, Snipes JA, Zhang J, Horvath EM, Figureroa JP, Szabo C, Busija DW: Lack of mitochondrial nitric oxide production in the brain. J Neurochem 2004;90:942-951.

- 31 Lacza Z, Pankotai E, Csordas A, Gero D, Kiss L, Horvath EM, Kollai M, Busija DW, Szabo C: Mitochondrial NO and reactive nitrogen species production: does mtNOS exist? Nitric Oxide 2006;14:162-168

32 Katakam PV, Wappler E, Katz P, Rutkai I, Institoris A, Domoki F, Gáspár T, Grovenburg SM, Snipes JA, Busija DW: Depolarization of mitochondria in endothelial cells promotes cerebral vascular vasodilation by activation of nitric oxide synthase. Arterioscler Thromb Vasc Biol 2013;33:752-759.

33 Meng W, Tobin JR, Busija DW: Glutamateinduced cerebral vasodilation is mediated by nitric oxide through N-methyl-D-aspartate receptors. Stroke 1995;26:857-862.

34 Lacza Z, Kozlov AV, Pankotai E, Csordas A, Wolf G, Redl H, Kollai M, Szbo C, Busija DW, Horn TFW: Mitochondria produce reactive nitrogen species via an arginine-independent pathway. Free Radic Res 2006;40:369-378.

35 Förstermann U: Nitric oxide and oxidative stress in vascular disease. Pflugers Arch 2010; 459:923-939.

- 36 Gaspar T, Snipes JA, Busija AR, Kis B, Domoki F, Bari F, Busija DW: ROS-independent preconditioning in neurons via activation of mitoK $_{\text {ATP }}$ channels by BMS-191095. J Cereb Blood Flow Metab 2008;28:1090-1103.

37 Rajapakse N, Kis B, Horiguchi T, Snipes J, Busija D: Diazoxide pretreatment induces delayed preconditioning in astrocytes against oxygen glucose deprivation and hydrogen peroxide-induced toxicity. J Neurosci Res 2003;73:206-214

38 Han D, William E, Cadenas E: Mitochondrial respiratory chain-dependent generation of superoxide anion and its release into the intermembrane space. Biochem J 2001;353:411416.

39 Yang W, Hekimi S: A mitochondrial superoxide signal triggers increased longevity in um 2007;42:447-466.
Caenorhabditis elegans. PLoS Biol 2010;8: e1000556.

40 Votyakova TV, Reynolds IJ: DeltaPsi(m)-dependent and -independent production of reactive oxygen species by rat brain mitochondria. J Neurochem 2001;79:266-277.

41 Wojtovich AP, Smith CO, Haynes CM, Nehrke KW, Brookes PS: Physiological consequences of complex II inhibition for aging, disease, and the $\mathrm{mK}_{\mathrm{ATP}}$ channel. Biochim Biophys Acta 2013;1827:598-611.

42 Muller FL, Liu Y, Van Remmem H: Complex III releases superoxide to both sides of the inner mitochondrial membrane. J Biol Chem 2004;279:49064-49073.

43 Jastroch M, Divakaruni AS, Mookerjee S, Treberg JR, Brand MD: Mitochondrial proton and electron leaks. Essays Biochem 2010;47:53-67.

-44 Bienert GP, Møller AL, Kristiansen KA, Schulz A, Møller IM, Schjoerring JK, Jahn TP: Specific aquaporins facilitate the diffusion of hydrogen peroxide across membranes. J Biol Chem 2007;282:1183-1192.

45 Calamita G, Ferri D, Gena P, Liquori GE, Cavalier A, Thomas D, Svelto M: The inner mitochondrial membrane has aquaporin-8 water channels and is highly permeable to water. J Biol Chem 2005;280:17149-17153.

46 Marchissio MJ, Francés DE, Carnovale CE, Marinelli RA: Mitochondrial aquaporin- 8 knockdown in human hepatoma HepG2 cells causes ROS-induced mitochondrial depolarization and loss of viability. Toxicol Appl Pharmacol 2012;64:246-254.

47 Quinlan CL, Perevoschikova IV, Goncalves RL, Hey-Mogensen M, Brand MD: The determination and analysis of site-specific rates of mitochondrial reactive oxygen species production. Methods Enzymol 2013;526:189-217.

48 Zhang DX, Gutterman DD: Mitochondrial reactive oxygen species-mediated signaling in endothelial cells. Am J Physiol Heart Circ Physiol 2007;292:H2023-H2031.

49 Rajapakse N, Shimizu K, Snipes J, Lacza Z, Busija D: Activation of mitochondrial ATPsensitive potassium channels prevents neuronal cell death after ischemia in neonatal rats. Neurosci Lett 2002;327:208-212.

$50 \mathrm{Lu}$ B, Poirier C, Gaspar T, Gratzke C, Harrison W, Busija D, Matsuk M, Andersson KE, Overbeek PA, Bishop CE: A mutation in the inner mitochondrial membrane peptidase 2-like gene (Immp2l) affects mitochondrial function and impairs fertility in mice. Biol Reprod 2008;78:601-610

51 Katakam PV, Jordan JE, Snipes JA, Tulbert CD, Miller AW, Busija DW: Myocardial preconditioning against ischemia-reperfusion is abolished in Zucker obese rats with insulin. Am J Physiol Regul Integr Comp Physiol 2007;292:R920-R926.

52 Katakam PV, Domoki F, Snipes JA, Busija AR, Jarajapu YP, Busija DW: Impaired mitochondria-dependent vasodilation in cerebral arteries of Zucker obese rats with insulin resistance. Am J Physiol Regul Integr Comp Physiol 2009;296:R289-R298. 
53 Brown KA, Didion SP, Andresen JJ, Faraci FM: 67 Wojtovich AP, Smith CO, Haynes CM, NehEffects of aging, MnSOD deficiency, and genetic background on endothelial function: evidence for MnSOD haploinsufficiency. Arterioscler Thromb Vasc Biol 2007;27:1941-1946.

54 Pung YF, Sam WJ, Hardwick JP, Yin L, Ohanyan V, Logan S, Di Vincenzo L, Chilian WM: The role of mitochondrial bioenergetics and reactive oxygen species in coronary collateral growth. Am J Physiol Heart Circ Physiol 2013;305:H1275-H1280.

- 55 Han D, Antunes F, Canali R, Rettori D, Cadenas E: Voltage-dependent anion channels control the release of the superoxide anion from mitochondria to cytosol. J Biol Chem 2003;278:5557-5563.

-56 Dikalova AE, Bikineyeva AT, Budzyn K, Nazarewicz RR, McCann L, Lewis W, Harrison DG, Dikalov SI: Therapeutic targeting of mitochondrial superoxide in hypertension. Circ Res 2010;107:106-116.

57 Zinkevich NS, Gutterman DD: ROS-induced ROS release in vascular biology: redox-redox signaling. Am J Physiol Heart Circ Physiol 2011;301:H647-H653.

58 Nazarewicz RR, Dikalova AE, Bikineyeva A, Dikalov SI: Nox2 as a potential target of mitochondrial superoxide and its role in endothelial oxidative stress. Am J Physiol Heart Circ Physiol 2013;305:H1131-H1140.

59 Chrissobolis S, Faraci FM: Sex differences in protection against angiotensin II-induced endothelial dysfunction by manganese superoxide dismutase in the cerebral circulation. Hypertension 2010;55:905-910.

60 Miller JD, Peotta VA, Chu Y, Weiss RM, Zimmerman K, Brooks RM, Heistad DD: MnSOD protects against COX1-mediated endothelial dysfunction in chronic heart failure. Am J Physiol Heart Circ Physiol 2010;298:H1600H1607.

-61 Ardehali H, O'Rourke B: Mitochondrial K(ATP) channels in cell survival and death. J Mol Cell Cardiol 2005;39:7-163.

-62 Foster DB, Ho AS, Rucker J, Garlid AO, Chen L, Sidor A, Garlid KD, O'Rourke B: Mitochondrial ROMK channel is a molecular component of mitoK(ATP). Circ Res 2012; 111:446-454.

63 Seharaseyon J, Ohler A, Sasaki N, Fraser H, Sato T, Johns DC, O’Rourke B, Marbán E: Molecular composition of mitochondrial ATP-sensitive potassium channels probed by viral Kir gene transfer. J Mol Cell Cardiol 2000;32:1923-1930.

-64 Lacza Z, Snipes JA, Kis B, Szabo C, Grover G, Busija DW: Investigation of the subunit composition and the pharmacology of the mitochondrial ATP-dependent $\mathrm{K}^{+}$channel in the brain. Brain Res 2003;19:27-36.

-65 Lacza Z, Snipes JA, Miller AW, Czabo C, Grover G, Busija DW: Heart mitochondria contain functional ATP-dependent $\mathrm{K}^{+}$channels. J Mol Cell Cardiol 2003;35:1339-1347.

-66 Rines AK, Bayeva M, Ardehali H: A new pROM king for the mitoK $\mathrm{ATP}_{\text {TT }}$ dance: ROMK takes the lead. Circ Res 2012;111:392-393. rke KW, Brookes PS: Physiological consequences of complex II inhibition for aging, disease, and the $\mathrm{mK}_{\mathrm{ATP}}$ channel. Biochim Biophys Acta 2013;1827:598-611.

68 Perez-Pinzon MA, Dave KR, Raval AP: Role of reactive oxygen species and protein kinase $\mathrm{C}$ in ischemic tolerance in the brain. Antioxid Redox Signal 2005;7:1150-1157.

69 Perez-Pinzon MA: Mechanisms of neuroprotection during ischemic preconditioning: lessons from anoxic tolerance. Comp Biochem Physiol 2007;147:291-299.

70 Hanley PJ, Gopalan KV, Lareau RA, et al: Betaoxidation of 5-hydroxydecanoate, a putative blocker of mitochondrial ATP-sensitive potassium channels. J Physiol 2003;547:387-393.

71 Busija DW, Katakam P, Rajapakse NC, Kis B, Grover G, Domoki F, Bari F: Effects of ATPsensitive potassium channel activators diazoxide and BMS-191095 on membrane potential and reactive oxygen species production in isolated piglet mitochondria. Brain Res Bull 2005;66:85-90.

72 Farkas E, Domoki F, Institoris A, et al: Neuroprotection by diazoxide in animal models for cerebrovascular disorders. Vasc Dis Prev

73 Coetzee WA: Multiplicity of effectors of the cardioprotective agent, diazoxide. Pharmacol Ther 2013;140:167-175

74 Kis B, Rajapakse N, Snipes JA, Nagy K, Horiguchi T, Busija DW: Diazoxide induces delayed preconditioning in cultured rat cortical neurons. J Neurochem 2003;87:969-980.

75 Lenzser G, Kis B, Bari F, Busija DW: Diazoxide preconditioning attenuates global cerebral ischemia-induced blood-brain barrier permeability. Brain Res 2005;105:72-80.

76 Busija DW, Gaspar T, Domoki F, Katakam PV, Bari F: Mitochondrial-mediated suppression of ROS production upon exposure of neurons to lethal stress: mitochondrial targeted preconditioning. Adv Drug Deliv Rev 2008;16:1471-1477. Busija DW: Opening of mitochondrial ATPsensitive potassium channels is a trigger of 3-nitropropionic acid-induced tolerance to transient focal cerebral ischemia in rats. Stroke 2003;34:1015-1020.

78 Grover GJ, Burkett DE, Parham CS, Scalese RJ, Sadanaga KK: Protective effect of mitochondrial $\mathrm{K}_{\mathrm{ATP}}$ activation in an isolated gracilis model of ischemia and reperfusion in dogs. J Cardiovasc Pharmacol 2003;42:790792.

79 Grover GJ, Burkett DE, Parham CS, Scalese RJ, Sadanaga KK: Protective effect of mitochondrial $K_{\text {ATP }}$ activation in an isolated gracilis model of ischemia and reperfusion in dogs. J Cardiovasc Pharmacol 2003;42:790-792.

$\$ 80$ Bednarczyk P, Koziel A, Jarmuszkiewicz W, Szewczyk A: Large-conductance $\mathrm{Ca}^{2+}$-activated potassium channel in mitochondria of endothelial EA.hy926 cells. Am J Physiol Heart Circ Physiol 2013;304:H1415-H1427. 2006;3:253-263.

77 Horiguchi T, Kis B, Rajapakse N, Shimizu K,
81 Gaspar T, Katakam P, Snipes JA, Kis B, Domoki F, Bari F, Busija DW: Delayed neuronal preconditioning by NS1619 is independent of calcium activated potassium channels. J Neurochem 2008;105:1115-1128.

82 Gaspar T, Domoki F, Lenti L, Katakam PVG, Snipes JA, Bari F, Busija DW: Immediate neuronal preconditioning with NS1619. Brain Res 2009;1285:196-207.

83 Tretter L, Adam-Vizi V: Uncoupling without an effect on the production of reactive oxygen species by in situ synaptic mitochondria. J Neurochem 2007;103:1864-1871.

84 Domoki F, Kis B, Gáspár T, Snipes JA, Bari F, Busija DW: Rosuvastatin induces delayed preconditioning against oxygen-glucose deprivation in cultured cortical neurons. Am J Physiol 2009;296:C97-C105.

85 Domoki F, Perciaccante JV, Veltkamp R, Bari F, Busija DW: Mitochondrial potassium channel opener diazoxide preserves neuronal-vascular function after cerebral ischemia in newborn pigs. Stroke 1999;30:2713-2718.

-86 Domoki F, Bari F, Nagy K, Busija DW, Siklos L: Diazoxide prevents mitochondrial swelling and $\mathrm{Ca}^{2+}$ accumulation in CA1 pyramidal cells after cerebral ischemia in newborn pigs. Brain Res 2004;1019:97-104.

87 Gaspar T, Kis B, Snipes JA, Lenzser G, Mayanagi K, Bari F, Busija DW: Neuronal preconditioning with the antianginal drug, bepridil. J Neurochem 2007;102:595-608.

88 Horiguchi T, Snipes JA, Kis B, Shimizu S, Busija DW: The role of nitric oxide in the development of cortical spreading depressioninduced tolerance to transient focal cerebral ischemia in rats. Brain Res 2005;1039:84-89.

89 Horiguchi T, Kis B, Rajapakse N, Shimizu K, Busija DW: Cortical spreading depression (CSD)-induced tolerance to transient focal cerebral ischemia in halothane anesthetized rats is affected by anesthetic level but not ATP-sensitive potassium channels. Brain Res 2005;1062:127-133.

-90 Loukogeorgakis SP, Williams R, Panagiotidou AT, Kolvekar SK, Donald A, Cole TJ, Yellon DM, Deanfield JE, MacAllister RJ: Transient limb ischemia induces remote preconditioning and remote postconditioning in humans by a K(ATP)-channel dependent mechanism. Circulation 2007;116:1386-1395.

91 Mayanagi K, Gaspar T, Katakam PV, Kis B, Busija DW: The mitochondrial K(ATP) channel opener BMS-191095 reduces neuronal damage after transient focal cerebral ischemia in rats. J Cereb Blood Flow Metab 2007;27: 348-355.

92 McIntosh VJ, Lasley RD: Adenosine receptormediated cardioprotection: are all 4 subtypes required or redundant? J Cardiovasc Pharmacol Ther 2012;17:21-33.

-93 Robin E, Simerabet M, Hassoun SM, Adamczyk S, Tavernier B, Vallet B, Bordet R, Lebuffe G: Postconditioning in focal cerebral ischemia: role of the mitochondrial ATP-dependent potassium channel. Brain Res 2011;1375: 137-146. 
$\$ 94$ Shimizu K, Lacza Z, Rajapakse N, Horiguchi T, Snipes J, Busija DW: MitoK ${ }_{\text {ATP }}$ opener, diazoxide, reduces neuronal damage after middle cerebral artery occlusion in the rat. Am J Physiol Heart Circ Physiol 2002;283: H1005-H1011.

95 Broadhead MW, Kharbanda RK, Peters MJ, MacAllister RJ: $\mathrm{K}_{\text {ATP }}$ channel activation induces ischemic preconditioning of the endothelium in humans in vivo. Circulation 2004;110:2077-2082.

$\$ 96$ Gidday JM: Cerebral preconditioning and ischaemic tolerance. Nat Rev Neurosci 2006; $7: 437-448$.

97 Kirino T: Ischemic tolerance. J Cereb Blood Flow Metab 2002;22:1283-1296.

$\$ 98$ Zhao $\mathrm{H}$ : Ischemic postconditioning as a novel avenue to protect against brain injury after stroke. J Cereb Blood Flow Metab 2009; 29:873-885.

99 Levin SG, Godukhin OV: Comparative roles of ATP-sensitive $\mathrm{K}^{+}$channels and $\mathrm{Ca}^{2+}$-activated $\mathrm{BK}^{+}$channels in posthypoxic hyperexcitability and rapid hypoxic preconditioning in hippocampal CA1 pyramidal neurons in vitro. Neurosci Lett 2009;461:90-94.

100 Debska G, Kicinska A, Dobrucki J, Dworakowska B, Nurowska E, Skalska J, Dolowy K, Szewczyk A: Large-conductance $\mathrm{K}^{+}$channel openers NS1619 and NS004 as inhibitors of mitochondrial function in glioma cells. Biochem Pharmacol 2003;65:1827-1834.

-101 Veltkamp R, Domoki F, Bari F, Busija DW: Potassium channel activators protect the NMDA-induced cerebral vascular dilation after combined hypoxia and ischemia in piglets. Stroke 1998;29:837-843.

102 Bari F, Louis TM, Busija DW: Calcium-activated $\mathrm{K}^{+}$channels in cerebral arterioles in piglets are resistant to ischemia. J Cereb Blood Flow Metab 1997;17:1152-1156.

103 Kicinska A, Szewczyk A: Large-conductance potassium cation channel opener NS1619 inhibits cardiac mitochondria respiratory chain. Toxicol Mech Methods 2004;14:5961.

104 Korper S, Nolte F, Rojewski MT, Thiel E, Schrezenmeier $\mathrm{H}$ : The $\mathrm{K}^{+}$channel openers diazoxide and NS1619 induce depolarization of mitochondria and have differential effects on cell $\mathrm{Ca}^{2+}$ in CD34+ cell line KG-1a. Exp Hematol 2003;31:815-823.

105 Harrell JW, Morgan BJ, Schrage WG: Impaired hypoxic cerebral vasodilation in younger adults with metabolic syndrome. Diab Vasc Dis Res 2013;10:135-142.

106 Gaspar T, Kis B, Snipes J, Lenzser G, Mayanagi K, Bari F, Busija D: Transient glucose and amino acid deprivation induces delayed preconditioning in cultured rat cortical neurons. J Neurochem 2006;98:555-565.

107 Pelligrino DA, Vetri F, Xu HL: Purinergic mechanisms in gliovascular coupling. Semin Cell Dev Biol 2011;22:229-236.
108 You J, Johnson TD, Marrelli SP, Bryan RM Jr: Functional heterogeneity of endothelial P2 purinoceptors in the cerebrovascular tree of the rat. Am J Physiol 1999;277:H893-H900.

109 Auchampach JA, Gross GJ: Adenosine A1 receptors, $\mathrm{K}_{\mathrm{ATP}}$ channels, and ischemic preconditioning in dogs. Am J Physiol 1993; 264:H1327-H1336.

110 Dietrich HH, Horiuchi T, Xiang C, Hongo K, Falck JR, Dacey RG Jr: Mechanism of ATP-induced local and conducted vasomotor responses in isolated rat cerebral penetrating arterioles. J Vasc Res 2009;46:253264.

111 Xi Q, Cheranov SY, Jaggar JH: Mitochondria-derived reactive oxygen species dilate cerebral arteries by activating $\mathrm{Ca}^{2+}$ sparks. Circ Res 2005;97:354-362.

112 Kemper MF, Zhao Y, Duckles SP, Krause DN: Endogenous ovarian hormones affect mitochondrial efficiency in cerebral endothelium via distinct regulation of PGC-1 isoforms. J Cereb Blood Flow Metab 2013;33: 122-128.

113 Cheranov SY, Jaggar JH: Mitochondrial modulation of $\mathrm{Ca}^{2+}$ sparks and transient $\mathrm{K}_{\mathrm{Ca}}$ currents in smooth muscle cells of rat cerebral arteries. J Physiol 2004;556:755-771.

$\checkmark 114$ Oldendorf WH, Cornford ME, Brown WJ: The large apparent work capacity of the blood-brain barrier: a study of the mitochondrial content of capillary endothelial cells in brain and other tissues of the rat. Ann Neurol 1977;1:409-417.

115 Koller A, Toth P: Contribution of flow-dependent vasomotor mechanisms to the autoregulation of cerebral blood flow. J Vasc Res 2012;49:375-389.

116 Behringer EJ: Aging impairs electrical conduction along endothelium of resistance artries through enhanced $\mathrm{Ca}^{2+}$-activated $\mathrm{K}^{+}$ channel activation. Artrioscler Thromb Vasc Biol 2013;33:1892-1901.

117 Razmara A, Sunday L, Stirone C, Wang XB, Krause DN, Duckles SP, Procaccio V: Mitochondrial effects of estrogen are mediated by estrogen receptor alpha in brain endothelial cells. J Pharmacol Exp Ther 2008;325:782790.

118 Busija DW, Heistad DD: Factors involved in the physiological regulation of the cerebral circulation. Rev Physiol Biochem Pharmacol 1984;101:161-211.

119 Dauphin F, MacKenzie ET: Cholinergic and vasoactive intestinal polypeptidergic innervation of the cerebral arteries. Pharmacol Ther 1995;67:385-417.

120 Toda N, Okamura T: Nitroxidergic nerve: regulation of vascular tone and blood flow in the brain. J Hypertens 1996;14:423-434.

121 Katakam PVG, Wappler E, Dutta S, Busija DW: Mitochondria-dependent cerebral artery vasodilation is mediated by the activation of neuronal nitric oxide synthase following mitochondrial depolarization of perivascular nerves (abstract). FASEB J 2012;26:1058-1059.
122 Ayajiki K, Tanaka T, Okamura T, Toda N: Evidence for nitroxidergic innervation in monkey ophthalmic arteries in vivo and in vitro. Am J Physiol 2000;279:H2006-H2012.

123 Jiang K, Wang J, Zhao C, Feng M, Shen Z, Yu Z, Xia Z: Regulation of gap junctional communication by astrocytic mitochondrial $\mathrm{K}(\mathrm{ATP})$ channels following neurotoxin administration in in vitro and in vivo models. Neurosignals 2011;19:63-74.

124 Kis B, Nagy K, Snipes JA, Rajapakse N, Horiguchi T, Grover GJ, Busija DW: The mitochondrial $\mathrm{K}_{\text {АTP }}$ channel opener BMS191095 induces neuronal preconditioning. Neuroreport 2004;15:345-349.

125 Kizhakekuttu TJ, Wang J, Dharmashankar K, Ying R, Gutterman DD, Vita JA, Widlansky ME: Adverse alterations in mitochondrial function contribute to type 2 diabetes mellitus-related endothelial dysfunction in humans. Arterioscler Thromb Vasc Biol 2012;32:2531-2539.

126 Erdös B, Snipes JA, Miller AW, Busija DW: Cerebrovascular dysfunction in Zucker obese rats is mediated by oxidative stress and protein kinase C. Diabetes 2004;53:13521359.

127 Erdös B, Simandle SA, Snipes JA, Miller AW, Busija DW: Potassium channel dysfunction in cerebral arteries of insulin-resistant rats is mediated by reactive oxygen species. Stroke 2004;35:964-969.

128 Erdös B, Snipes JA, Tulbert C, Katakam P, Miller AW, Busija DW: Rosuvastatin improves cerebrovascular function in Zucker obese rats by inhibiting $\mathrm{NAD}(\mathrm{P}) \mathrm{H}$-oxidasedependent superoxide anion production. Am J Physiol Heart Circ Physiol 2006;290: H1264-H1270.

129 Bari F, Louis TM, Meng W, Busija DW: Global ischemia impairs ATP-sensitive $\mathrm{K}^{+}$ channel function in cerebral arterioles in piglets. Stroke 1996;27:1874-1881.

130 Mayanagi K, Katakam PV, Gaspar T, Domoki F, Busija DW: Acute treatment with rosuvastatin protects insulin resistant (C57BL/6) $\mathrm{ob} / \mathrm{ob}$ ) mice against transient cerebral ischemia. J Cerebral Blood Flow Metab 2008;28: 1927-1935.

131 Makino A, Scott BT, Dillmann WH: Mitochondrial fragmentation and superoxide anion production in coronary endothelial cells from a mouse model of type 1 diabetes. Diabetologia 2010;53:1783-1794.

132 Domoki F, Kis B, Nagy K, Farkas E, Busija DW, Bari F: Diazoxide preserves hypercapnia-induced arteriolar vasodilation after global cerebral ischemia in piglets. Am J Physiol 2005;289:H368-H373.

133 Rutkai I, Dutta S, Liu D, Katakam PVG, Busija DW: Enhanced cerebrovascular response to mitochondrial depolarization following middle cerebral artery occlusion. Soc Neurosci Abstr 2013;144.05/L6. 